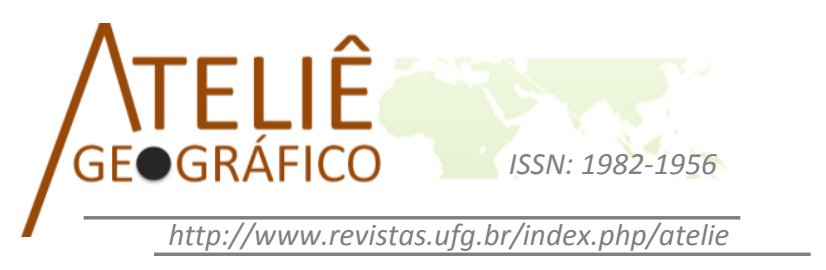

\title{
Percepção da qualidade ambiental urbana no bairro Santa Cruz em Luís Eduardo Magalhães (BA)
}

\author{
Perception of environmental quality in Santa Cruz, urban \\ neighborhood of Luis Eduardo Magalhães city, Bahia state \\ Percepción de la calidad del medio ambiente urbano en el
barrio de Santa Cruz en Luís Eduardo Magalhães (BA)
}

Franco Porto dos Santos

Universidade Federal do Tocantins

francobio@hotmail.com

Lucas Barbosa e Souza

Universidade Federal do Tocantins

lbsgeo@uft.edu.br

\begin{abstract}
Resumo
A qualidade ambiental pode ser entendida como o conjunto das condições otimizadas ótimas que regem o comportamento do espaço habitável, podendo ser atribuída por meio de indicadores quantitativos e de indicadores perceptivos. Dessa maneira, o presente artigo estudou a percepção da qualidade ambiental dos moradores do bairro Santa Cruz, município de Luís Eduardo Magalhães (BA), obedecendo às recomendações para os trabalhos de campo dessa natureza, com base no triângulo metodológico formado pela conjunção das abordagens ouvindo, perguntando e observando. Visou levantar informações relativas às experiências dos sujeitos, assim como suas percepções, julgamentos e avaliações dos problemas ambientais vivenciados por eles. Os resultados demonstraram, dentre outras coisas, que os sujeitos investigados, em sua maioria, percebem a qualidade ambiental do bairro como ruim, principalmente em comparação aos demais setores da cidade, e que os problemas ambientais mais percebidos e que mais incomodam são esgoto a céu aberto e disposição inadequada de resíduos sólidos.
\end{abstract}

Palavras-chave: Qualidade ambiental. Percepção Ambiental. Luís Eduardo Magalhães (BA).

\footnotetext{
Abstract

The environmental quality can be understood as the set of optimal conditions that govern the behavior of habitable space and can be assigned by means of quantitative and perceptive indicators. Thus, this study analyzed the perception of the environmental quality by the residents of the Santa Cruz district, municipality of Luís Eduardo Magalhães (BA), Brazil, following the recommendations for this type of
} 
field work, based on the methodological triangle formed by the combination of listening, asking, and observing. This study aimed to gather information on the individuals' perceptions, judgments, and evaluations about the environmental problems they experience. Results showed among other things that the majority of the investigated individuals perceive the neighborhood environmental quality as poor, especially in comparison to other sectors of the city. The perceived environmental problems that more bothered them are open sewer and improper disposal of solid waste.

Keywords: Environmental Quality. Environmental Perception. Luís Eduardo Magalhães (BA), Brazil.

\begin{abstract}
Resumen
La calidad del medio ambiente puede ser entendida como el conjunto de condiciones óptimas que rigen el comportamiento del espacio habitable y se pueden asignar a través de indicadores cuantitativos e indicadores perceptivos. Así, este artículo se refiere al estudio de la percepción de la calidad ambiental de los residentes del barrio de Santa Cruz, municipio de Luís Eduardo Magalhães (BA), de acuerdo con las recomendaciones para ese tipo de trabajo de campo, basado en el triángulo formado por la combinación de los enfoques metodológicos de escucha, preguntas y observación. La investigación se dirige a recoger información sobre las experiencias de los sujetos, así como sus percepciones, juicios y evaluaciones de los problemas ambientales que experimentan. Los resultados mostraron, entre otras cosas, que los sujetos investigados, la mayoría percibe la calidad ambiental de la zona como muy mala, especialmente en comparación con otros sectores de la ciudad, y que los más grandes problemas ambientales percibidos y que molestan más, son el alcantarillado al aire libre y el destino inadecuado de los residuos sólidos.
\end{abstract}

Palabras clave: Calidad Ambiental. Percepción Ambiental. Luís Eduardo Magalhães (BA).

\title{
Introdução
}

A população mundial, nas últimas décadas, passou a se concentrar nos centros urbanos, o que tem gerado, na maioria das vezes, o crescimento espacial das cidades (RODRIGUES et al., 2010). No Brasil, essa tendência também é verificada, sendo que a ampliação das áreas urbanas, frequentemente, tem ocorrido de forma rápida, desordenada e, portanto, sem um planejamento adequado, sendo este um dos motivos pelos quais as cidades vêm sofrendo com problemas ambientais (LACERDA et al., 2010; MUCELIN; BELLINI, 2008; PIVETTA; SILVA FILHO, 2002).

Diante deste cenário, o poder público não tem conseguido atender de modo satisfatório a todas as demandas decorrentes do aumento populacional urbano. Logo, observa-se a necessidade de ações de planejamento e de gestão, na medida em que estes subsidiam a organização do espaço urbano e sua melhor qualidade ambiental (SILVA, 2012). 
Para Gomes e Soares (2004, p. 27 e 28), "só é possível conceber um ambiente como dotado de 'boa qualidade' desde que este apresente satisfação pessoal ao homem, em todas as dimensões da vida humana". Assim, situações como esgoto a céu aberto, disposição inadequada de lixo, invasão de áreas verdes, desrespeito às áreas públicas, diversos tipos de poluição; bem como as mais diferentes formas de mazelas sociais, são algumas das muitas dificuldades que fazem com que as cidades sejam "ilhas" de problemas, quando se fala em ambientes sustentáveis (BATISTA, 2006).

Ainda segundo Gomes e Soares (2004, p. 27 e 28), "a salubridade de cada lugar não pode ser percebida nem tão pouco compreendida se não se pensar que aquele lugar está sendo produzido pelo homem e para o homem". Desse modo, este artigo aborda aspectos da qualidade ambiental do bairro Santa Cruz, município de Luís Eduardo Magalhães (BA), por meio do estudo da percepção dos moradores locais. Luís Eduardo Magalhães é uma cidade em que o crescimento da infraestrutura urbana não acompanhou o aumento da população e a ampliação da área urbana, o que contribuiu para o surgimento de alguns problemas ambientais, principalmente relacionados à presença de esgoto e de lixo, carência de árvores, poluição sonora e do ar. O Santa Cruz é o bairro mais populoso e um dos mais antigos da cidade, sendo aquele que apresenta as maiores carências em relação à infraestrutura.

\section{Qualidade, planejamento e gestão do ambiente urbano}

A qualidade ambiental pode ser entendida como o conjunto das condições ótimas que regem o comportamento do espaço habitável em termos de conforto associado ao ecológico, biológico, econômico-produtivo, socialcultural, tipológico e estático, em suas dimensões espaciais (LUENGO, 1998).

Por esses motivos, a determinação dos níveis de qualidade ambiental, principalmente nos ambientes urbanos, torna-se uma tarefa difícil devido à complexidade dos elementos envolvidos e que devem ser avaliados. Para Borja (1997), cada grupo social tem demandas especificadas em relação ao meio ambiente urbano, respaldadas em concepções de vida, desejos e necessidades culturalmente construídas. Esses grupos ou agentes sociais, conforme Corrêa (1995), fazem e refazem o espaço urbano, sendo que cada um tem interesses diferenciados em relação à terra urbana.

Com base em Machado (1997), a qualidade ambiental pode ser atribuída por meio de indicadores quantitativos (critérios objetivos) e de indicadores perceptivos (critérios subjetivos), o que torna a sua determinação complexa. Entretanto, para esta autora, se aliados os dois tipos de critérios (objetivos e subjetivos), pode-se ter um retrato mais fiel dessa qualidade, pois o 
meio ambiente urbano, conforme as especificidades dos seus elementos, produz uma qualidade ambiental que pode ser maléfica ou benéfica para nossa vida.

Assim, entende-se por boa qualidade ambiental urbana a associação dos parâmetros físicos, químicos, biológicos, sociais, políticos, econômicos e culturais que permitam o desenvolvimento harmonioso, pleno e digno da vida, ou seja, a qualidade ambiental urbana resulta de processos diretamente relacionados à sociedade-natureza (TROPPMAIR, 1992), até mesmo porque, conforme Rodrigues (1998), a questão ambiental deve ser compreendida como um produto da intervenção da sociedade sobre a natureza. Diz respeito não apenas a problemas relacionados à natureza, mas às problemáticas decorrentes da ação social.

Segundo Gomes e Soares (2004), a qualidade do meio ambiente é, em parte, objeto da percepção humana, pois a organização dos elementos naturais e artificiais possibilita o gosto ou o repúdio ao ambiente, sendo uma questão de preferência, uma questão de estética, porém mais do que isso, é uma questão de funcionalidade que passa necessariamente pela organicidade do espaço urbano.

Lynch (1999, p. 331), esclarece que "os locais não são apenas o que são, mas a percepção que temos deles". Baseado no autor, a boa forma urbana requer uma cidade que seja vital, sensível, adequada, acessível e bem controlada. Em termos gerais, um lugar contínuo, bem conectado, aberto e que contribua para o desenvolvimento. Segundo ele (LYNCH, 1999, p. 117 e 118), existem pelo menos cinco dimensões básicas e dois meta-critérios que são medidas inclusivas da qualidade de um aglomerado populacional, sendo eles respectivamente: vitalidade, sentido, adequação, acesso, controle, eficiência e justiça. Sendo assim, é preciso que os aglomerados populacionais tenham uma série de qualidades, para que os seus moradores possam ficar satisfeitos e criar elos com o local onde vivem. Além disso, Tuan (1980; 1983) explica que o sentimento pode se tornar uma fonte de conhecimento e de identificação entre homem e lugar. Para Machado (1997), a influência do meio ambiente nos sentimentos, relacionando as múltiplas sensações do ser humano à complexidade do conceito de qualidade de vida e ambiental, estão intimamente associados. Ou seja, a dificuldade de delimitação de ambos impede as definições mais exatas, mas permite a verificação de formas diferenciadas a partir de critérios objetivos e subjetivos.

No geral, as propostas de adensamento ou de parcelamento do solo observados no meio urbano apenas se preocupam com a disponibilidade de infraestrutura mínima, deixando de lado outros requisitos importantes, dentre eles a qualidade e a distribuição de espaços livres que possam permitir o saudável contato do cidadão com a natureza e as possibilidades de socialização e expressão cultural. Dessa forma, percebe-se que a realidade brasileira é bem 
diferente do ideal, pois na maioria dos casos observados no país, os processos de urbanização ocorrem a partir de um planejamento inadequado ou da ausência deste, gerando um crescimento desordenado, acompanhado da falta da infraestrutura adequada e de outros fatores capazes de garantir a mínima qualidade ambiental (UGEDA JÚNIOR; AMORIM, 2009).

O surgimento e a expansão de cidades sem um adequado planejamento infraestrutural pode refletir negativamente na qualidade de vida dos moradores, pois o crescimento urbano desordenado aliado à concentração e à desigualdade de renda, entre outras consequências, pode provocar distúrbios e inseguranças sociais, como também a degradação ambiental. A partir dessa compreensão, torna-se clara a constatação de que os centros urbanos têm sofrido muito com sua expansão não planejada, fato que está diretamente relacionado com o desequilíbrio ambiental. Na urbanização, os seres humanos transformam ambientes naturais, criando outros artificialmente, formando uma complexa teia de intervenções para atender a todas as suas necessidades como seres sociais, o que pode implicar em problemas relacionados ao ambiente, a sua conservação e qualidade. Logo, é importante conhecer a diversidade dos aspectos do meio ambiente urbano, para que se possa melhorar a qualidade de vida dentro desses espaços (SILVA, 2002).

Segundo Rodrigues (1998), o debate da questão ambiental extrapola a cidade e compreende a própria forma como a sociedade se relaciona com a natureza. Assim, o meio ambiente urbano poderia ser representado, também, pela problemática ambiental, que se torna fundamental para pensar o passado, presente e futuro, pautada na análise da produção socioespacial. O espaço urbano seria ao mesmo tempo realidade real e virtual, o espaço da ciência e da técnica, que produz e reproduz as relações socioespaciais. Dessa maneira, a vida nas cidades se torna importante e ganha destaque, haja vista as condições do meio físico urbano, que adquiriu características peculiares decorrentes da ação antrópica intensificada e, consequentemente, com a aquisição de novos padrões de vida decorrentes também da urbanização (GOMES; SOARES, 2004).

Nesse contexto, é cada vez maior a necessidade do planejamento ambiental urbano, considerando que a condição ambiental degradada desfavorece a qualidade de vida, devido às modificações na paisagem e à estruturação do espaço, representada pelos novos agentes de transformação (MINAKI; AMORIM, 2007). Para as autoras, as condições ambientais, em grande parte das cidades, não são suficientes para proporcionar qualidade de vida adequada à população, visto que se verifica a degradação do ambiente, a falta de condições sanitárias e de infraestrutura, carências que muitas vezes são decorrentes de investimentos públicos insuficientes. 
Para Souza (2006, p. 21 e 22), "o ato de planejar pode ser entendido como uma ação racional em busca de um objetivo pré-definido, a fim de que os esforços não sejam desperdiçados". Ao contrário, "a ideia de gestão pressupõe a efetivação de ações (planejadas ou não) no momento presente". Segundo o autor, a orientação do tempo é a principal distinção entre o planejamento e a gestão, por isso, "as ações previstas para o futuro fazem parte do planejamento e suas concretizações no presente fazem parte da gestão".

Souza (2004), anteriormente, salientava que planejamento e gestão são conceitos complementares e não antagônicos. Planejar significa tentar simular os desdobramentos de um processo, visando precaver-se de prováveis problemas e/ou potencializar os benefícios. Para o autor, o poder público está, na maioria das vezes, diante de necessidade imediatas, pois há um enorme descompasso entre a manifestação dos problemas urbanos e a sua solução, o que explica a priorização da gestão em detrimento do planejamento, na atualidade.

Nos ambientes urbanos, a constante relação dialética entre o homem e o ambiente é preponderante para a qualidade dos mesmos. Desse modo, no planejamento e na gestão dos processos de urbanização, a qualidade do ambiente urbano torna-se um dos aspectos importantes para a determinação da qualidade de vida da população, uma vez que, sob o ponto de vista social, a necessidade de avaliação da qualidade ambiental decorre do aumento da consciência de que problemas ambientais podem afetar a saúde e o bem estar da população (BANDEIRA, 2010). Entretanto, de acordo com os interesses de cada ator ou grupo social, essa preocupação pode estar presente ou não, motivo pelo qual a legislação deve normatizar suas ações em prol do bem coletivo.

Além disso, deve-se ter a formulação de diretrizes gerais de administração do ambiente urbano, com ênfase na gestão democrática, orientando o poder público a agir com transparência e a levar em consideração a participação popular. Assim, tem grande importância no âmbito dos processos de planejamento e de gestão do meio ambiente urbano.

Para Souza (2004), a participação popular pode contribuir para minimizar certas fontes de distorção. Além disso, os instrumentos de planejamento e as rotinas de gestão, por mais relevantes e criativos que sejam, só adquirem plena legitimidade ao terem a sua operacionalização e a sua implementação debatidas, deliberadas e monitoradas pelos cidadãos (SOUZA, 2006).

Nesse sentido, Ribeiro (2004) explica que todas as propostas de planejamento visando ao desenvolvimento sustentável ressaltam a importância da participação da comunidade no processo de tomada de decisões e, sobretudo, na implantação de estratégias. Para o autor, o sujeito ou grupo que 
conhece a realidade e, a partir de então, tenta encontrar soluções adequadas, geralmente está mais apto a promover um desenvolvimento socioeconômico menos agressivo ao meio ambiente e dessa forma, mais sustentável.

\section{Caracterização da área de estudo}

O município de Luís Eduardo Magalhães (LEM), localizado na região Oeste da Bahia, faz divisa com o estado do Tocantins e tem 13 anos de emancipação política. Nesse período, aumentou em mais de $200 \%$ a sua população, passando de 18 mil habitantes (às vésperas da emancipação), quando a localidade ainda era distrito do município de Barreiras e se chamava Mimoso do Oeste, para os mais de 60 mil habitantes que apresenta atualmente (IBGE, 2011a; 2011b).

Esse crescimento populacional se deu em função de o município estar inserido numa região de fronteira agrícola e se tornar um dos mais importantes pólos do agronegócio do Brasil. No entanto, apesar de todo esse desenvolvimento econômico, a cidade apresenta sérios problemas ambientais e de infraestrutura, o que em parte pode ser justificado pelo seu exagerado aumento populacional em curto intervalo de tempo.

O bairro Santa Cruz corresponde à primeira área periférica da cidade, sendo criado no ano de 1986, quando LEM ainda era apenas um povoado do município de Barreiras. Para Oliveira (2012), o setor imobiliário e a elite local determinaram o processo de periferização planejada do referido bairro, que ocorreu precocemente, ocasionando uma segregação socioespacial da cidade.

Santos (2008) também cita o bairro Santa Cruz, em sua tese, ao afirmar que as desigualdades econômicas e sociais são realçadas no município, que é considerado exemplo de desenvolvimento para o modelo agrícola implantado na região. Para ele, este bairro é onde reside uma parcela de trabalhadores rurais desempregados e trabalhadores que exercem atividades de uma economia submergida, ou seja, da economia informal, muitas vezes como autônomos ou fazendo apenas trabalhos temporários. Ainda segundo o autor, no Santa Cruz, a violência, a prostituição infantil e as drogas convivem com o esgoto correndo a céu aberto e, por ser tão violento, até poucos anos atrás era conhecido popularmente como "Iraque", em referência ao país que apresentava caráter belicoso e de constantes disputas e guerras.

O bairro Santa Cruz também teve destaque numa investigação realizada pelos autores do presente artigo, que diagnosticaram os problemas ambientais urbanos de Luís Eduardo Magalhães por meio da análise das reclamações ambientais registradas na Secretaria Municipal de Meio Ambiente. 
Esse trabalho demonstrou que o bairro foi aquele que teve o maior número de registro de reclamações no órgão ambiental, concentrando 35\% do total.

Para Vieira (2007), o bairro Santa Cruz foi criado pelos agentes imobiliários que, percebendo a leva de imigrantes com baixa ou nenhuma renda que chegava à cidade, delimitaram uma área para lotes menores e mais baratos, destinados a esta população. Hoje, o bairro se diferencia dos demais devido à precária infraestrutura habitacional, com habitações improvisadas ou avenidas de lotes subdivididos.

Apesar de todos os aspectos negativos relatados anteriormente, observa-se que o bairro vem melhorando significativamente suas condições urbanísticas, por meio da maior presença do poder público mais recentemente, que começa a perceber a necessidade de um tratamento prioritário que o mesmo requer. Atualmente, segundo informações da Prefeitura Municipal, o bairro conta com sete escolas municipais, uma escola estadual e uma creche, sendo atendidos mais de 5.500 estudantes. Tem duas unidades de saúde e é onde se localizam o Centro de Educação Ambiental e o Viveiro de Mudas do município, o Mercado Municipal e a Companhia da Polícia Militar. Além disso, tem-se observado construções importantes no âmbito de praças e de escolas públicas, ginásio de esportes, estádio municipal, assim como pavimentação de muitas ruas, situações observadas durante os trabalhos de campo, em agosto e setembro de 2012.

\section{Metodologia}

A operacionalização da pesquisa obedeceu às recomendações de Whyte (1977) para os trabalhos de campo em percepção ambiental, com base no triângulo metodológico formado pela conjunção de três tipos distintos de abordagens: perguntando, observando e ouvindo. Tais abordagens foram concretizadas por intermédio do emprego de diferentes técnicas de coleta de dados, como coleta de descrições verbais sobre o tema da pesquisa (abordagem ouvindo), entrevistas dirigidas (abordagem perguntando) e observações indiretas (abordagem observando), que visaram levantar informações relativas às experiências dos sujeitos, assim como suas percepções, julgamentos e avaliações dos problemas ambientais vivenciados por eles.

A etapa ouvindo consistiu em coletar descrições de 20 moradores do bairro Santa Cruz por meio de um enunciado chave: "como você descreve o meio ambiente do bairro Santa Cruz?". As descrições foram trabalhadas com base no método fenomenológico, seguindo as orientações de Giorgi (2008), sendo realizada a redução fenomenológica de todas as descrições e, posteriormente, a identificação das essências, que foram sistematizadas e 
categorizadas em uma tabela, que representa a síntese das essências (unidades de significação).

A coleta de descrições precedeu a realização das entrevistas, no intuito de que as questões formuladas fossem baseadas nos sentidos revelados pelos próprios sujeitos nas descrições, e não a partir de hipóteses previamente pensadas pelo pesquisador (GIORGI, 2008). A partir das essências identificadas, foi formulado um roteiro para as entrevistas dirigidas, observando-se as recomendações de Whyte (1977), no intuito de refinar a investigação e aprofundar as principais questões presentes nas descrições da etapa anterior.

Conforme dito anteriormente, foi realizado um diagnóstico ambiental com base nas reclamações ambientais registradas na secretaria municipal de meio ambiente, que dentre outras coisas, demonstrou a quantidade de reclamações por bairro. Assim, os 20 sujeitos participantes dessa estratégia foram selecionados de maneira aleatória do grupo que compunha os reclamantes do bairro santa cruz.

A estratégia perguntando consistiu em entrevistar 32 moradores do bairro santa cruz por meio de um roteiro estruturado. Esse grupo foi dividido em dois, sendo selecionados 16 sujeitos que já realizam algum tipo de registro de reclamação ambiental na secretaria municipal de meio ambiente e que participaram da estratégia ouvindo ${ }^{1}$, e 16 sujeitos que nunca registraram reclamação ambiental, no sentido de diversificar a amostra. Estes também foram selecionados aleatoriamente, levando em consideração apenas a localização espacial das casas dos sujeitos, para se ter uma maior distribuição possível dos entrevistados por todo o bairro estudado.

assim como as descrições, as entrevistas foram coletadas nas residências dos sujeitos por meio de um gravador digital e transcritas de imediato. O roteiro foi organizado em duas partes, sendo a primeira composta por uma ficha de registro dos dados pessoais dos sujeitos e de um espaço para anotação das observações do entorno da moradia dos entrevistados, e a segunda constituída por 10 perguntas, sendo nove abertas e apenas uma fechada. Além disso, existiam duas questões que foram direcionadas apenas aos sujeitos que fizeram reclamações ambientais e outras duas apenas aos sujeitos que nunca registraram reclamação ambiental em órgão público.

por último, a estratégia observando se deu em toda a área do bairro. No entanto, houve especial atenção ao entorno das moradias dos sujeitos da

\footnotetext{
${ }^{1}$ A intenção era entrevistar os mesmos 20 sujeitos da estratégia ouvindo. No entanto, quatro deles não foram encontrados para a aplicação da estratégia perguntando, mesmo diante de inúmeras tentativas.
} 
pesquisa. Desse modo, a técnica da observação indireta foi aplicada concomitante às entrevistas, consistindo em observar os elementos caracterizadores da qualidade ambiental e os indicadores da conduta dos moradores no bairro (presença de lixo, de esgoto a céu aberto e de lotes baldios, falta de pavimentação nas ruas, arborização, dentre outros).

\section{Resultados e discussão}

Os resultados serão apresentados e discutidos seguindo a ordem das estratégias de pesquisa. Assim, espera-se traçar um panorama acerca da percepção ambiental deste grupo de moradores do bairro Santa Cruz.

\section{Descrições - Estratégia Ouvindo}

Os sujeitos fizeram as descrições de maneira livre e espontânea, relatando o que julgassem pertinentes quando levados a descrever o meio ambiente do bairro Santa Cruz. A redução fenomenológica foi realizada em todas as descrições, seguida pela identificação das essências, observando o método de Giorgi (2008), conforme o exemplo:

\section{Descrição do Meio Ambiente do Bairro Santa Cruz}

"Temos aqui uma rede de esgoto que não tá funcionando, temos a questão dos lava jatos que funcionam sem uma padronização, sem fiscalização, jogando água no meio da rua, muitas vezes furando poço de qualquer jeito. E aqui não é específico ao bairro, mas em relação à LEM, o cemitério e o lixão ficam sobre uma área onde passa o aquífero Urucuia, onde foi feita pesquisa e talvez esse aquífero esteja contaminado pelo necrochorume e chorume do lixão. Temos aqui também, doenças relacionadas à qualidade da água, hepatites, por exemplo, porque a água que vem pra gente já tá contaminada".

\section{Redução Fenomenológica}

O bairro não tem sistema de esgotamento sanitário e alguns empreendimentos funcionam fora das normas ambientais, perfurando poços tubulares de qualquer jeito e jogando esgoto na rua. Há falta de fiscalização dos órgãos competentes. Alguns problemas abrangem toda a cidade como a possível contaminação do aquífero Urucuia devido à localização inapropriada do lixão e do cemitério da cidade.

Essências Identificadas

- Ausência de sistema de esgotamento sanitário.

- Perfuração de poço tubular para captação de água sem autorização. 
- Funcionamento de empreendimentos fora das normas ambientais.

- Falta de fiscalização ambiental pelos órgãos competentes.

- Contaminação do aquífero Urucuia pela localização do lixão e do cemitério.

A descrição apresentada é a transcrição integral da fala do sujeito em resposta ao enunciado apresentado. Segundo Giorgi (2008), busca-se obter uma descrição concreta da experiência do sujeito, sendo que em nosso caso trata-se de uma experiência em relação ao ambiente. A redução fenomenológica é a descrição reapresentada na linguagem da pesquisa. Já a essência identificada é a estrutura do fenômeno, obtida pela identificação da unidade de significado expressa na fala do sujeito, a partir da releitura da descrição e da redução.

A discussão dos resultados tomou como base a síntese das essências identificadas no conjunto das descrições dos sujeitos, que foram sistematizadas na Tabela 1.

Tabela 1. Essências identificadas na descrição do meio ambiente do bairro Santa Cruz.

\begin{tabular}{l|c|c}
\hline \multicolumn{1}{c|}{ Essências Identificadas } & Descrições/Sujeitos & Frequência \\
\hline $\begin{array}{l}\text { Problemática do lixo disposto irregularmente pela falta de } \\
\text { consciência dos moradores e de interesse do poder público. }\end{array}$ & $\begin{array}{c}\text { D5, D12, D15, D17, } \\
\text { D19, D20 }\end{array}$ & 07 \\
\hline Carência de árvores no bairro e necessidade de arborização. & $\begin{array}{c}\text { D2, D8, D10, D11, D16, } \\
\text { D20 }\end{array}$ & 06 \\
\hline $\begin{array}{l}\text { Problemática do esgoto a céu aberto pela ausência de sistema de } \\
\text { esgotamento sanitário no bairro. }\end{array}$ & D1, D3, D17, D19 & 04 \\
\hline Não sabe descrever o meio ambiente do bairro. & D13, D18 & 02 \\
\hline Excesso de poeira no bairro pela falta de pavimentação nas ruas. & D8, D14 & 02 \\
\hline $\begin{array}{l}\text { Funcionamento de empreendimentos comerciais fora das } \\
\text { normas, que jogam esgoto na rua e perfuram poço tubular sem } \\
\text { autorização. }\end{array}$ & D3 & 01 \\
\hline $\begin{array}{l}\text { O meio ambiente do bairro é avaliado negativamente porque há } \\
\text { muita poluição sonora. }\end{array}$ & D4 & 01 \\
\hline A prefeitura não está cuidando do meio ambiente. & D6 & 01 \\
\hline $\begin{array}{l}\text { A qualidade do meio ambiente melhorou devido à redução dos } \\
\text { buracos na rua. }\end{array}$ & D7 & 01 \\
\hline Bairro tranquilo pela baixa incidência de roubos. & D10 \\
\hline $\begin{array}{l}\text { Falta planejamento e infraestrutura de trânsito, como } \\
\text { sinalização, passarela, ponto de ônibus. }\end{array}$ & D16 \\
\hline $\begin{array}{l}\text { A construção do balneário público às margens do rio de Pedras } \\
\text { é um ponto positivo. }\end{array}$ & D3 & 01 \\
\hline Falta de fiscalização ambiental pelos órgãos competentes. & D3 & 01 \\
\hline $\begin{array}{l}\text { Contaminação do aquífero Urucuia pela localização do lixão e } \\
\text { do cemitério. }\end{array}$ & & 01 \\
\hline Fonte: Pesquisa de Campo & \\
\hline
\end{tabular}

Fonte: Pesquisa de Campo. 
Ao descreverem o meio ambiente do bairro Santa Cruz, a essência que se destacou, com sete ocorrências, conforme Tabela 1 , estava relacionada à problemática do lixo nas ruas e em terrenos baldios. A essência ainda mostra que, para os sujeitos, há falta de consciência da população e de interesse do poder público em resolver essa questão, conforme pode ser visualizado nas descrições a seguir:

\footnotetext{
"Eu vejo o meio ambiente como ruim [...]. A questão da educação, tanto das pessoas como do poder público, que não faz nada para tirar os resíduos de material como borracha, sacola que a gente vê jogado nos terrenos baldios. Eu não vejo preocupação nenhuma, tanto das pessoas como do poder público" (Sujeito D17).

"[...] e o povo também é muito relaxado porque lixo vai para a rua" (Sujeito D19).
}

A "carência de árvores no bairro e necessidade de arborização" para a melhoria do ambiente também foi uma essência que teve expressividade, com seis ocorrências. Como se observa nas descrições a seguir, os sujeitos relacionam a qualidade ambiental com a boa arborização, informando que o meio ambiente "precisa melhorar" devido à pequena quantidade de árvores no bairro.

\begin{abstract}
"Tem que melhorar muita coisa, o meio ambiente daqui está muito precário. Assim, falta muita árvore que não tem aqui no bairro, não tem muita sombra, acho que tem que melhorar muita coisa [...]" (Sujeito D10).
\end{abstract}

A terceira essência mais representativa, com quatro ocorrências, diz respeito à problemática do esgoto a céu aberto, visto que o bairro ainda não tem sistema de esgotamento sanitário funcionando. Essa informação demonstra que a população também se sente incomodada com a ausência desse serviço de saneamento básico, principalmente por relacionar o esgoto a céu aberto com problemas na saúde pública. Dessa maneira, a falta de sistema de esgotamento sanitário indicaria que o ambiente não é "saudável", além do mau cheiro, que pode ser percebido facilmente pelos próprios moradores.

Outras essências foram identificadas, embora de maneira menos recorrente, indicando que a percepção dos aspectos ambientais do bairro também pode estar ligada, por exemplo, à poluição sonora e hídrica, à falta de fiscalização municipal, à questão da infraestrutura urbana. Isso demonstra a variedade de critérios pelos quais as pessoas avaliam a qualidade ambiental.

No geral, as pessoas fizeram descrições que evidenciaram os problemas ambientais do local, problemas estes que os afetam diretamente, que causam 
desconforto. Verificou-se também, que os moradores mais recentes tendem a apresentar percepções mais negativas, enquanto moradores mais antigos normalmente demonstram percepções mais positivas, embora isso não seja uma regra. Isso pode ocorrer devido àqueles primeiros moradores conseguirem perceber as melhorias, talvez por terem mais raízes no local e ficarem contentes e esperançosos por isso.

\section{Entrevistas - Estratégia Perguntando}

Com o intuito de aprofundar a investigação sobre a percepção ambiental dos moradores do bairro Santa Cruz, a partir das essências identificadas na abordagem ouvindo, passou-se à realização da abordagem perguntando, que consistiu em entrevistas dirigidas, conforme explicado anteriormente.

As informações possibilitaram caracterizar o grupo de sujeitos entrevistados, que era composto por 15 homens e 17 mulheres e apresentava diferentes faixas etárias. A maior parte dos sujeitos (18 pessoas) era de adultos na faixa dos 20 aos 40 anos de idade. O nível de escolaridade também ficou bem distribuído entre faixas que variaram desde os analfabetos àqueles que possuíam nível superior, sendo o nível de ensino fundamental aquele que teve o maior número de entrevistados, com 10 sujeitos.

Em relação às profissões dos sujeitos entrevistados, todas são profissões que, em geral, exigem baixa escolaridade. O tempo de moradia no bairro Santa Cruz também foi um dado coletado, por estar diretamente relacionado à questão da percepção ambiental, pois, para Tuan (1983), a criação de laços topofílicos com os lugares depende da duração e da intensidade da experiência com os mesmos. Por sua vez, os aspectos topofílicos são influenciados e também influenciam a percepção ambiental. Apenas um sujeito morava há menos de um ano no bairro Santa Cruz. A maioria (17 sujeitos) morava há 11 anos ou mais, ou seja, praticamente residia no local desde a emancipação do município de Luís Eduardo Magalhães. Dessa maneira, houve também uma satisfatória distribuição dos sujeitos no aspecto do tempo de moradia no bairro, indicando, de maneira ampla, um grupo de sujeitos com larga experiência com a área de estudo, o que contribui para que os mesmos a conheçam de forma íntima e duradoura, credenciando-os a participar da pesquisa.

A seguir, serão apresentadas as perguntas realizadas aos sujeitos e os quadros com a sistematização das essências identificadas nas respostas. No entanto, é importante salientar que na estratégia perguntando, diferentemente da estratégia ouvindo, não houve o processo da redução fenomenológica, pois 
apesar da maioria das perguntas serem abertas, as respostas, na maioria dos casos, foram mais curtas e diretas, ao contrário das descrições obtidas na primeira abordagem. Dessa forma, as essências contidas nas respostas foram identificadas diretamente, sem a referida redução, sendo posteriormente agrupados nos referidos quadros.

Na primeira questão "Liste os problemas ambientais do bairro Santa Cruz", os sujeitos foram levados a listar os problemas ambientais percebidos no bairro (Quadro 1). A pergunta aberta teve o objetivo de identificar os problemas que mais incomodam os sujeitos entrevistados, sem, no entanto, dar opções aos mesmos. Cada entrevistado poderia listar vários problemas, caso desejasse.

Quadro 1. Essências identificadas nas respostas à questão "Liste os problemas ambientais do bairro Santa Cruz".

\begin{tabular}{|c|l|c|c|}
\hline \multicolumn{2}{|l|}{ PROBLEMAS AMBIENTAIS } & ENTREVISTADOS & FREQUÊNCIA \\
\hline $\mathbf{0 1}$ & $\begin{array}{l}\text { Disposição inadequada de lixo nas ruas e } \\
\text { em terrenos baldios. }\end{array}$ & $\begin{array}{l}\text { P1; P3; P4; P5; P8; P9; P10; } \\
\text { P13; P15; P20; P21; P22; } \\
\text { P23; P24; P25; P30; P31; }\end{array}$ & 18 \\
\hline $\mathbf{0 2}$ & $\begin{array}{l}\text { Falta de sistema de esgotamento } \\
\text { sanitário. }\end{array}$ & $\begin{array}{l}\text { P4; P5; P7; P8, P11; P12; } \\
\text { P16; P17; P18; P22; P27 }\end{array}$ & 11 \\
\hline $\mathbf{0 3}$ & Não percebe problemas ambientais. & P6; P14; P26; P28; P29 & 05 \\
\hline $\mathbf{0 4}$ & Falta de árvores. & P4; P5 & 02 \\
\hline $\mathbf{0 5}$ & $\begin{array}{l}\text { Realização de queimadas, principalmente } \\
\text { em terrenos baldios. }\end{array}$ & P4; P32 \\
\hline $\mathbf{0 6}$ & $\begin{array}{l}\text { Falta de drenagem de águas pluviais, que } \\
\text { ocasiona alagamentos. }\end{array}$ & P18; P27 & 02 \\
\hline $\mathbf{0 7}$ & $\begin{array}{l}\text { Falta de coleta seletiva de lixo e de } \\
\text { cooperativas para trabalhar nessa área. }\end{array}$ & P7 & 01 \\
\hline $\mathbf{0 8}$ & Falta de planejamento urbano. & P2 & 01 \\
\hline $\mathbf{0 9}$ & Poeira. & P23 & 01 \\
\hline $\mathbf{1 0}$ & População com menor poder aquisitivo. & 01 \\
\hline & \multicolumn{2}{|c|}{ TOTAL } \\
\hline
\end{tabular}

Fonte: Entrevistas realizadas pelo autor, em agosto/2012.

Com base nas informações anteriores, foi possível observar que o problema que mais incomoda é referente ao lixo nas ruas e em terrenos baldios do bairro, com 18 ocorrências, seguido pelo escoamento de esgoto a céu aberto, com 11 ocorrências. O que chama atenção é o fato de cinco entrevistados não perceberem nenhum tipo de problema ambiental no bairro. Supostamente essas pessoas não percebem os problemas existentes como "ambientais" ou então suas experiências anteriores e conhecimento acumulado impedem que o problema ambiental seja percebido como tal, com a possibilidade dos impactos terem se tornado habituais e não necessariamente reconhecidos como "problemas". 
Na segunda questão, "Dos problemas ambientais que vou te mostrar, qual te incomoda mais?", foi mostrado um quadro com as seguintes opções: esgoto a céu aberto, lixo nas ruas e em terrenos baldios, falta de árvores, poeira, som de carros e bares, coleta de lixo mal feita, queimadas. As opções listadas procuraram contemplar as situações observadas no bairro e na cidade, além de aspectos relacionados nas descrições da abordagem ouvindo, característica confirmada por meio do teste realizado com o roteiro de questões, aplicado previamente em outro grupo de sujeitos não participantes da pesquisa. A questão também teve o objetivo de verificar os problemas que mais incomodam os moradores (Quadro 2). No entanto, difere da primeira porque é uma questão objetiva ou fechada, sendo dadas opções aos moradores, que poderiam escolher apenas uma.

Quadro 2. Essências identificadas nas respostas à questão "Dos problemas ambientais que vou te mostrar, qual te incomoda mais?".

\begin{tabular}{|c|l|c|c|}
\hline \multicolumn{2}{|c|}{ PROBLEMAS AMBIENTAIS } & ENTREVISTADOS & FREQUÊNCIA \\
\hline $\mathbf{0 1}$ & Esgoto a céu aberto. & $\begin{array}{c}\text { P6; P7; P9; P12; P16; P17; P19; } \\
\text { P21; P24; P26; P28; P30 }\end{array}$ & 12 \\
\hline $\mathbf{0 2}$ & $\begin{array}{l}\text { Lixo nas ruas e em terreno } \\
\text { baldio. }\end{array}$ & $\begin{array}{c}\text { P5; P8; P13; P15; P18; P20; P22; } \\
\text { P23; P25; P29; P31 }\end{array}$ & 11 \\
\hline $\mathbf{0 3}$ & Som de carros e de bares. & P1; P2; P3; P4; P10; P11; P27; & P32 \\
& & P14 & 08 \\
\hline $\mathbf{0 4}$ & Poeira. & - & 01 \\
\hline $\mathbf{0 5}$ & Falta de árvores. & - & - \\
\hline $\mathbf{0 6}$ & Coleta de lixo mal feita. & - & - \\
\hline $\mathbf{0 7}$ & Queimadas. & & 32 \\
\hline \multicolumn{2}{|c|}{ TOTAL } \\
\hline
\end{tabular}

Fonte: Entrevistas realizadas pelo autor, em agosto/2012.

Nas respostas dessa pergunta, houve uma alteração na ordem dos problemas que mais incomodam. Aqui, o esgoto a céu aberto teve uma frequência maior que a problemática do lixo, embora com uma diferença mínima. Uma situação que chama atenção é que a poluição sonora ocasionada por som de carros e de bares, que teve oito ocorrências, nem sequer foi mencionada nas respostas da primeira questão. Talvez a poluição sonora não seja percebida, a princípio, como um problema ambiental. Por isso, nas respostas espontâneas essa categoria não apareceu na lista de essências identificadas. Porém, quando estimulado por um rol de alternativas, há uma ampliação das opções que podem ser apontadas como problemas ambientais.

Para Lynch (1999, p. 124), ao relatar sobre os ruídos da cidade: 
Só agora começam a ser analisadas as implicações para a saúde do ruído e das luzes da cidade. O ruído tem sido considerado apenas como uma perturbação menor e a iluminação como uma simples comodidade, cuja intensidade deve ser aumentada logo que o dinheiro o permita. Atualmente, sabe-se que ambas as emissões têm efeitos diretos sobre a saúde e efeitos indiretos importantes, na medida em que podem reforçar ou perturbar os ritmos do corpo humano: afetar o nosso sono ou dessincronizar as flutuações normais das funções internas.

Dessa maneira, a população pode sentir os efeitos negativos da poluição sonora devido a sua possível interferência na saúde das pessoas e, consequentemente, na qualidade de vida das mesmas. Assim, esse tipo de poluição pode causar nos moradores o sentimento de antipatia pelo local, causada pelo desconforto que os ruídos provocam.

A terceira questão "Para você, quem é o principal responsável pelo problema que mais te incomoda?" visou verificar, entre os moradores, os principais responsáveis pelos problemas ambientais percebidos (Quadro 3). Como era uma questão aberta, os moradores poderiam elencar vários responsáveis.

Quadro 3. Essências identificadas nas respostas à questão "Para você, quem é o principal responsável pelo problema que mais te incomoda?".

\begin{tabular}{|c|l|c|c|}
\hline $\begin{array}{c}\text { REPONSÁ VEL PELOS PROBLEMAS } \\
\text { AMBIENTAIS }\end{array}$ & ENTREVISTADOS & FREQUENCIA \\
\hline $\mathbf{0 1}$ & Prefeitura, Autoridade, & P5; P8; P10; P11; P12; P13; & \\
& Poder Público. & P14; P15; P17; P18; P20; & 20 \\
& & P21; P22; P23; P24; P25; & \\
& & P26; P27; P30; P32 & 14 \\
\hline $\mathbf{0 2}$ & População, Morador, & P11; P16; P19; P23; P28; & \\
& Comunidade. & P29; P31 & 01 \\
\hline $\mathbf{0 3}$ & Empresários. & P3 & 35 \\
\hline \multicolumn{2}{|c|}{ TOTAL } \\
\hline
\end{tabular}

Fonte: Entrevistas realizadas pelo autor, em agosto/2012.

As respostas evidenciaram que a maioria (20 sujeitos) acredita que o poder público é o principal responsável pelos problemas listados nas questões 1 e 2. Dessa maneira, os sujeitos deixam claro que percebem a conduta negligente do poder público frente aos problemas ambientais. No entanto, 14 sujeitos também responderam que a responsabilidade é da população, morador ou comunidade, reconhecendo a importância de cada indivíduo na prevenção dos problemas ambientais. Apenas um sujeito citou os empresários como responsáveis, talvez pelo fato de terem vários estabelecimentos empresariais 
que praticam condutas inadequadas na disposição de resíduos sólidos, lançamentos de efluentes nas ruas e até mesmo abertura de poços tubulares sem a devida autorização do órgão competente. No entanto, essa relação (empresas/impactos) não é claramente percebida nas respostas da maior parte dos sujeitos, talvez porque tenham a noção de que a responsabilidade por controlar e fiscalizar as atividades empresariais seja do poder público.

A quarta questão "Como esse problema que mais te incomoda pode ser resolvido?" visou verificar as formas para resolução dos problemas (Quadro 4), segundo os sujeitos.

Quadro 4. Essências identificadas nas respostas à questão "Como esse problema que mais te incomoda pode ser resolvido?".

\begin{tabular}{|c|l|c|c|}
\hline $\begin{array}{c}\text { FORMAS PARA RESOLUÇÃO } \\
\text { DOS PROBLEMAS } \\
\text { AMBIENTAIS }\end{array}$ & ENTREVISTADOS & FREQUÊNCIA \\
\hline $\mathbf{0 1}$ & $\begin{array}{l}\text { Elaboração de Regras / } \\
\text { Fiscalização / Punição. }\end{array}$ & $\begin{array}{c}\text { P4; P5; P6; P8; P10; P11; } \\
\text { P13; P15; P17; P19; P20; } \\
\text { P22; P25; P27; P32 }\end{array}$ & 15 \\
\hline $\mathbf{0 2}$ & $\begin{array}{l}\text { Conscientização / } \\
\text { Iniciativa espontânea } \\
\text { dos próprios } \\
\text { moradores. }\end{array}$ & $\begin{array}{c}\text { P2; P3; P9; P23; P28; } \\
\text { P29; P31 }\end{array}$ & 07 \\
\hline $\mathbf{0 3}$ & $\begin{array}{l}\text { Medida estrutural } \\
\text { (obras) sob } \\
\text { responsabilidade do } \\
\text { Poder Público / } \\
\text { Melhoria dos Serviços } \\
\text { Públicos. }\end{array}$ & $\begin{array}{c}\text { P12; P14; P18; P21; P24; } \\
\text { P26; P30 }\end{array}$ & 07 \\
\hline $\mathbf{0 4}$ & $\begin{array}{l}\text { Projetos de Educação } \\
\text { Ambiental / } \\
\text { Campanhas } \\
\text { informativas. }\end{array}$ & P1; P7; P16 & 03 \\
\hline \multicolumn{2}{|c|}{ TOTAL } & 32 \\
\hline
\end{tabular}

Fonte: Entrevistas realizadas pelo autor, em agosto/2012.

As respostas para essa questão também foram livres e foram agrupadas conforme as suas características. Dessa maneira, boa parte acredita que o poder público, como principal responsável pelos problemas, deve elaborar regras, fiscalizar e punir os possíveis infratores (esperam por medidas coercitivas). Além disso, acreditam que os moradores precisam tomar consciência, para que estes tenham iniciativa espontânea para a redução dos problemas ambientais. Porém, conforme verificado na abordagem ouvindo, a atribuição de culpa é geralmente realizada aos "outros" (moradores, vizinhos) e, dificilmente 
assumida pelo próprio respondente. A construção de obras também foi uma essência identificada, principalmente do aterro sanitário, do sistema de esgotamento sanitário e de drenagem de águas pluviais, e a melhoria dos serviços no que se refere à coleta de lixo e limpeza pública em geral. Apenas três essências mencionaram ações socioeducativas para educação ambiental.

Tanto as medidas coercitivas (regras, fiscalização e multas) quanto às medidas estruturais (obras) são de atribuição do poder público, o que reforça a expectativa dos sujeitos de que os problemas sejam solucionados pelos governantes. Isso demonstra uma situação de tutela a que a sociedade brasileira foi habituada historicamente, ou seja, de que cabe exclusivamente ao poder instituído a solução dos problemas de ordem coletiva.

A quinta questão "Você já participou de atividades onde pudesse dar sugestões para a melhoria dos problemas ambientais do bairro?" visou verificar o nível de participação popular dos sujeitos. Nessa pergunta, oito sujeitos disseram que sim, que já participaram de atividades dessa natureza. Quando perguntados sobre quais foram essas atividades, as respostas foram: reunião da Associação de Moradores, reunião de discussão da "Lei do Silêncio", Conselho Municipal de Meio Ambiente, palestras promovidas pelas Secretarias Municipais, trabalho social de orientação a gestantes viciadas. No entanto, a maioria dos entrevistados (24 sujeitos) disse nunca ter participado de reuniões em que pudesse dar sugestões para a melhoria dos problemas ambientais. Desses 24 entrevistados, apenas seis pessoas relataram que não têm interesse em participar desse tipo de atividade por não acreditar na sua efetividade. Os demais (18 sujeitos) gostariam de participar de atividades de natureza democrática. Isso demonstra a necessidade de ampliação e fortalecimento das instâncias participativas no âmbito do bairro, uma vez que se verifica, de modo geral, certo potencial e receptividade da população para se engajar. Todavia, trata-se de um trabalho com características pedagógicas, que deve ser realizado de modo contínuo, no sentido de habituar os moradores à participação (SOUZA, 2004).

Para Souza (2004), a participação popular não elimina os erros e nem é garantia de acerto; no entanto, contribui para reduzir as fontes de distorção. Além disso, ao participar de uma decisão, o cidadão se sente muito mais responsável pelo seu resultado e passará a cuidar e a fiscalizar as ações decididas de maneira efetiva. Assim, pode proporcionar melhores chances do exercício mais pleno da cidadania, que equivale a maior e melhor integração na sociedade.

A sexta questão "Você sabe onde reclamar caso veja algum problema ambiental?" foi feita aos 16 sujeitos escolhidos aleatoriamente e que não fizeram reclamação ambiental junto à Prefeitura. Teve o objetivo de analisar o 
grau de informação dos sujeitos acerca dessa possibilidade, sendo que 11 sujeitos responderam que "não", que não sabem onde reclamar ao se depararem com algum problema ambiental. Os cinco sujeitos restantes responderam "sim", que sabem a quem recorrer, relatando as seguintes instâncias: Prefeitura/Secretaria de Meio Ambiente (três respostas), Vereador (uma resposta), Emissora de Rádio (uma resposta).

Esses resultados demonstram a importância da comunicação nos processos de planejamento e de gestão ambiental urbana. A comunicação, segundo Ribeiro (2004), aplicada a políticas de meio ambiente e desenvolvimento, deve ser um instrumento que permita aos tomadores de decisão e às populações analisar e compreender as situações insatisfatórias com que se defrontam, de discuti-las, de buscar melhorias e soluções para essas situações através de negociações e ações diretas. Além de informar deve, também, promover a formação de pessoas necessárias a tal empreitada. Ainda segundo a autora, a comunicação, ligada à educação ambiental, é um importante instrumento de mudança social, com uma forte dimensão política, na medida em que os sujeitos que participam de decisões que afetam suas vidas formam bases para a construção de uma sociedade civil democrática.

A sétima questão "Você acredita que as reclamações realizadas em órgãos públicos podem surtir um efeito prático?" também foi realizada apenas aos 16 sujeitos escolhidos de forma aleatória e que não fizeram reclamação ambiental. Teve o objetivo de verificar se os sujeitos acreditam nas ações dos órgãos públicos.

As respostas foram divididas, sendo que sete sujeitos acreditam que "não", não há efeito prático, alegando que muita gente reclama e que isso não é capaz de resolver o problema. No entanto, quatro sujeitos acreditam que "sim", que há efeito prático ao se fazer uma reclamação em órgãos públicos. Outras três pessoas também acreditam que "sim", mas somente se muitas pessoas reclamarem. Segundo os mesmos, reclamações isoladas surtem pouco efeito. Um sujeito relatou que "talvez" possa surtir efeito prático e outro sujeito informou que não sabe avaliar a questão.

A oitava questão, "Qual o principal motivo de você ter registrado reclamação na Secretaria do Meio Ambiente de Luís Eduardo Magalhães?", diferente das duas questões anteriores (6 e 7), foi feita aos 16 sujeitos que fizeram reclamação ambiental junto à ao órgão ambiental do município e que participaram da estratégia ouvindo. Objetivou conhecer o real motivo do registro das reclamações.

As respostas que mais se destacaram tenderam ao sentimento de incômodo com o problema ambiental, relatado por 11 sujeitos. Outros três sujeitos informaram que o problema estava afetando o desenvolvimento de sua 
atividade comercial; e outros dois que percebiam que o problema poderia afetar a saúde da população. Observa-se que a maioria dos sujeitos reclamou por conta do problema afetar de modo direto sua própria qualidade de vida ou objetivos pessoais, o que confirma a questão do individualismo na busca por soluções pelos problemas ambientais.

A nona questão "Sua reclamação surtiu algum efeito?" também foi feita apenas aos 16 sujeitos que fizeram reclamação ambiental e que participaram da estratégia ouvindo. Visou verificar o efeito da reclamação e o retorno do órgão. Cinco sujeitos responderam que "sim", pois o problema foi resolvido. Outros quatro sujeitos também responderam "sim", mas justificando que o problema diminuiu, mas não se resolveu completamente. Duas pessoas relataram que "talvez", pois o problema foi resolvido, embora nunca tenham recebido uma resposta do órgão, e outras cinco pessoas informaram que a reclamação ambiental realizada no órgão público competente não surtiu nenhum efeito, pois o problema persistiu.

Nessa questão, há certa vantagem para o sucesso da reclamação ambiental, embora o fracasso tenha tido números significativos. É importante que as reclamações surtam efeito, para que o procedimento seja percebido pela comunidade como algo realmente válido e eficaz. Caso contrário, haveria frustração da expectativa atribuída ao poder público (seu poder de fiscalização, coerção e reversão dos quadros denunciados), pois se trata de uma comunidade ainda pouco mobilizada no sentido de sua organização política interna.

A décima questão "Faça uma comparação entre o Santa Cruz e os outros bairros da cidade, em relação ao meio ambiente. Em outras palavras, qual a diferença entre o meio ambiente do Santa Cruz e dos outros bairro da cidade?" teve o objetivo de analisar como os sujeitos percebem o bairro onde moram em relação aos demais setores da cidade de Luís Eduardo Magalhães, dadas as características próprias do bairro, já comentadas anteriormente.

A maioria absoluta das respostas (20 sujeitos) acredita que o Santa Cruz é o pior bairro da cidade de Luís Eduardo Magalhães. As justificativas para isso variaram sob diferentes aspectos, sendo a maioria concentrada nas características da própria população, na alta criminalidade, na falta de infraestrutura ou de ações do poder público. Apenas um sujeito respondeu que o Santa Cruz é um bairro melhor que os demais. Outras 10 pessoas acreditam que o Santa Cruz é igual aos outros bairros da cidade. E, por fim, uma pessoa relatou que não sabia responder ao questionamento, apesar de dizer que o bairro melhorou nos últimos anos, principalmente pela diminuição do esgoto que flui pelas ruas.

Em relação às características da população residente no bairro, Vieira (2007) e Santos (2008) relataram que tem grande parcela de analfabetos ou 
semianalfabetos, de desempregados e de trabalhadores de baixa qualificação profissional, além dos mais baixos índices educacionais e de renda da cidade. Abaixo seguem duas respostas que exemplificam a percepção dos sujeitos perante o exposto:

"O Santa Cruz é o pior bairro da cidade devido à própria educação das pessoas" (Sujeito P1).

"Grande diferença, pois nos outros bairros vivem pessoas ricas, enquanto no Santa Cruz somente os fracos" (Sujeito P28).

Em relação à alta criminalidade, Vieira (2007) e Santos (2008) também relataram que o bairro é o principal reduto de violência, prostituição e drogas da cidade. Algumas respostas tenderam nesse sentido, como por exemplo:

"O bairro Santa Cruz é o pior devido à criminalidade" (Sujeito P2).

"Não há muita diferença, a não ser pelo fato de no Santa Cruz ter muita casa de prostituição e bares" (Sujeito P27).

Em se tratando de infraestrutura, o bairro se diferencia dos demais devido à precária infraestrutura, com habitações improvisadas e lotes subdivididos (VIEIRA, 2007). É a área de ocupação mais popular e historicamente pouco provida de infraestrutura urbana e saneamento básico, apresentando problemas socioambientais severos, segundo Oliveira (2012). Conforme se observa no exemplo abaixo, o lixo e o esgoto são grandes problemas:

"O Santa Cruz é o pior bairro, pois tem muito lixo e esgoto" (Sujeito P32).

Algumas respostas também indicam que alguns sujeitos acreditam que outros bairros da cidade são mais beneficiados pelo poder público, como se observa nos exemplos abaixo:

"O Mimoso I e o Jardim Paraíso são bairros mais limpos e organizados que o Santa Cruz, porque a prefeitura se preocupa mais com eles" (Sujeito P30).

"Há um descaso com o Santa Cruz em relação aos demais bairros" (Sujeito P31).

Conforme se observou nas respostas anteriores, há uma valorização negativa do bairro Santa Cruz por alguns sujeitos, que apresentam sentimento 
quase topofóbicos em suas falas. Conforme explicações de Sturza e Machado (2005, p. 348), "a topofobia, ainda pouco explorada pelos estudos geográficos, é a aversão ao lugar, traduzido também nas paisagens do medo, que são objetos de repulsão". Os autores, citando Amorim Filho (1999), esclareceram ainda que "a complexidade dos sentimentos implicados na topofobia dificulta a identificação e caracterização destes sentimentos e que geralmente, eles são muito confusos pela valorização negativa dada aos lugares" (STURZA; MACHADO, 2005, p. 348). Segundo eles, os sentimentos topofóbicos também estão relacionados aos aspectos estéticos, quando os lugares são considerados feios e desagradáveis, e à falta de segurança.

O único sujeito que acredita que o Santa Cruz está em situação melhor que os demais bairros da cidade, fez sua análise a partir das melhorias que vêm ocorrendo no local, conforme o relato abaixo:

"O bairro Santa Cruz está melhor que os demais bairros da cidade, pois melhora a cada dia" (Sujeito P6).

Alguns dos 10 sujeitos que responderam que o Santa Cruz está igual aos demais bairros da cidade colocaram o Centro e o Jardim Paraíso como os melhores setores, igualando todos os demais, como se observa nos exemplos a seguir.

"É igual ao outros bairros, pois esgoto, falta de árvores e som alto são problemas de toda a cidade" (Sujeito P4).

"É igual aos demais bairros, pois vem melhorando" (Sujeito P11).

As respostas revelam que a percepção dos moradores sobre o próprio bairro é, em geral, negativa, haja vista que a maioria colocou o Santa Cruz como um setor em situação pior que a dos demais. Observa-se também que as ações realizadas recentemente, principalmente na área de infraestrutura, começam a interferir positivamente na percepção de alguns sujeitos, pois estes reconhecem que o bairro vem passando por melhorias significativas.

\section{Observações - Estratégia Observando}

Por meio da estratégia observando foi possível verificar que a disposição inadequada de resíduos sólidos é um problema ambiental em todo o bairro Santa Cruz, assim como em vários pontos da cidade de Luís Eduardo Magalhães. De maneira geral, o serviço de limpeza pública do município não consegue atender satisfatoriamente ao bairro Santa Cruz, pois há resíduos 
espalhados pelas vias públicas e pelos terrenos desocupados, apresentando vários locais com grande acúmulo de lixo. Além disso, percebe-se que a fiscalização por parte de órgãos competentes não acontece a contento.

No entanto, verifica-se também que a população tem grande parcela de responsabilidade para a ocorrência desse tipo de problema ambiental, pois os resíduos sólidos muitas vezes não são destinados a locais apropriados ou são dispostos inadequadamente por empresários do ramo de materiais reciclados em ruas e calçadas, podendo ocasionar além da poluição do solo, poluição visual e proliferação de animais nocivos e transmissores de doenças.

Desse modo, esse é um dos grandes problemas ambientais urbanos de Luís Eduardo Magalhães, assim como um dos fatores que influenciam significativamente na percepção da qualidade ambiental urbana, conforme os resultados obtidos nas estratégias ouvindo e perguntando.

O esgoto a céu aberto é outro grande problema ambiental do bairro, haja vista que pode interferir diretamente, assim como a disposição inadequada de resíduos sólidos, na saúde da população. Foram vistos esgotos escorrendo por várias ruas. A maioria é formada por água servida liberada por habitações e até mesmo por empresas. Além disso, há também esgotos que se formam a partir do transbordo de fossas, o que gera transtornos ainda maiores devido ao mau cheiro e ao potencial de contaminação. O município ainda está implantando a rede de esgotamento sanitário e, por isso, os efluentes líquidos são destinados às fossas, sejam elas sépticas ou simplificadas. Nota-se, nesse caso, que assim como acontece com o problema dos resíduos sólidos, deveria haver maior fiscalização por parte dos órgãos competentes.

Foram observadas grandes quantidades de vias sem pavimentação no bairro, o que favorece a emissão de poeira em períodos de seca, e a formação de lama do período chuvoso, fatores que afetam diretamente a qualidade de vida da população. Observa-se também que essas ruas são desorganizadas, pois não possuem meio fio e, consequentemente, não há delimitação das calçadas, interferindo negativamente na acessibilidade dos moradores.

Essas observações apenas realçam os resultados obtidos na análise das abordagens ouvindo e perguntando. A falta de pavimentação nas ruas, por facilitar a emissão de poeira, influencia na poluição do ar e em outros aspectos do cotidiano da população, como na manutenção da limpeza interna das habitações, afetando a qualidade de vida dos moradores.

Por ocasião dos trabalhos de campo, ao longo de 2012, algumas ruas passavam ou tinham acabado de passar por melhorias na infraestrutura, principalmente quanto à pavimentação e à colocação de meio fio. Desse modo, é justo expor algumas dessas benfeitorias, pois as mesmas podem afetar a 
percepção dos moradores em relação ao bairro. A execução recente de outras obras também merece destaque, pois estas foram bastante comentadas pelos moradores, como por exemplo: praças, escolas, quadras poliesportivas, estádio municipal, balneário, dentre outras.

As melhorias realizadas no bairro certamente vêm influenciando, ainda que gradativamente, na percepção dos moradores quanto à qualidade ambiental do local. Nesse caso, remete-se ao exposto por Lynch (1999, p. 147) ao tratar da adequação de um aglomerado populacional. Para ele, "a adequação tem a ver com o local e com o comportamento real ou, quando muito, com o comportamento conscientemente desejado". Ainda segundo o autor,

\begin{abstract}
A adequação de um aglomerado populacional está relacionada com o modo com que o seu padrão espacial e temporal corresponde ao comportamento habitual dos seus habitantes. [...] Os locais são modificados para se adequarem a comportamentos e os comportamentos são alterados para se adequarem a um local. (LYNCH, 1999, p. 145).
\end{abstract}

Para Lynch, os locais necessitam de melhorias para a população poder senti-los como apropriados para serem habitados. Segundo ele:

\begin{abstract}
A adequação pode ser alcançada através da modificação do local, do comportamento, ou de ambos. Os meios de análise são a observação do comportamento real em determinado cenário, juntamente com uma análise dos problemas e das intenções das pessoas que utilizam esse cenário. [...] A criação de novos cenários adequados e a educação dos utilizadores no sentido de usarem corretamente os locais, são questões importantes assim como a melhoria dos cenários existentes. A compartimentação no espaço e no tempo, o controle do utilizador, e uma programação, supervisão e afinação cuidadosas são meios universais de aumentar a adequação atual. (LYNCH, 1999, p. 176).
\end{abstract}

Desse modo, as melhorias na infraestrutura do bairro, constatadas ao longo do presente estudo e verificadas também nas descrições dos sujeitos, têm papel importante na percepção e na melhoria da qualidade ambiental do bairro e da cidade.

Observou-se, também, que há áreas e ruas do bairro, principalmente aquelas do subcentro, onde fica a maior parte do comércio, que apresentam melhor infraestrutura. Isso porque o bairro Santa Cruz é o mais populoso de Luís Eduardo Magalhães e ocupa uma grande porção da área urbana do 
município. A ocupação do setor se deu por fases, por isso as áreas mais antigas apresentam melhores condições em relação à infraestrutura, como por exemplo: pavimentação, meio fio, iluminação pública, canteiro central.

Esses fatores também foram realçados em algumas descrições, pois os moradores, geralmente aqueles que vivem nas áreas de ocupação mais recentes e com menos infraestrutura, relataram que há locais no próprio bairro Santa Cruz que são "melhores" que os outros.

Os terrenos baldios ou ociosos também foram observados, em grande quantidade, especialmente na área periférica do bairro. Na maioria dos casos, verificou-se que os mesmos não possuem cercas, muros ou calçadas, o que facilita a disposição de lixo e a realização de queimadas por parte dos moradores. O município de LEM ainda não implantou o sistema de IPTU progressivo, embora o artigo 45 do Plano Diretor Urbano mencione essa possibilidade, sendo possível sua aplicação por meio de lei específica, que definirá as condições para a implementação, quando for o caso. Talvez pela inexistência desse instrumento da política urbana, esses terrenos são deixados para especulação imobiliária, sem que seus proprietários façam nenhuma benfeitoria.

A estratégia observando, conforme explicado anteriormente, teve como objetivo evidenciar alguns aspectos que foram relatados durante as descrições e entrevistas realizadas nas estratégias ouvindo e perguntando, respectivamente, bem como salientar outras características que não chegaram a ser comentadas de modo satisfatório. Servem também para que o leitor tenha uma melhor dimensão acerca das características urbanas e ambientais do bairro Santa Cruz, foco da pesquisa, notadamente aqueles aspectos observados ao longo dos trabalhos de campo.

\section{Considerações}

Os moradores do bairro Santa Cruz, em sua maioria, percebem a qualidade ambiental do bairro como ruim, principalmente em comparação aos demais setores da cidade. Isso pode ser justificado, dentre outras coisas, pela infraestrutura ainda precária do bairro e pelos altos índices de criminalidade, prostituição e drogas ainda flagrantes, que podem despertar sentimentos topofóbico nos sujeitos.

Nesse sentido, observa-se também que a população do bairro ainda exerce pouco controle social sobre a utilização e os acessos a espaços e atividades, assim como tem baixa participação nas ações de planejamento e gestão urbanos. Além disso, o modo como os benefícios e os custos ambientais é distribuído pela cidade se encontra desigual, pois a segregação socioespacial, 
a diferença na qualidade ambiental e no aspecto da infraestrutura dos bairros ainda são flagrantes na cidade, principalmente em desfavor do bairro Santa Cruz.

Dessa forma, com base nas especificidades observadas, é flagrante a necessidade de implantação de medidas preventivas que contribuam para o desenvolvimento do bairro e para a melhoria das condições de vida dos seus moradores. Essas devem buscam considerar a responsabilidade dos próprios moradores na manutenção ou na melhoria da qualidade ambiental de seu bairro e de sua cidade, de modo paralelo ao trabalho de outros atores sociais e sem reduzir o papel do poder municipal em cuidar do espaço urbano.

Considerando essa premissa, as necessidades estão relacionadas, dentre outros aspectos, à infraestrutura: implantação do aterro sanitário, do sistema de esgotamento sanitário e do sistema de drenagem de águas pluviais, construção de praças e jardins nos terrenos públicos e pavimentação de ruas; à comunicação e educação ambiental: elaboração de plano de comunicação para ações públicas na área ambiental, aproveitando as oportunidades de comunicação para intensificar as ações educativas no bairro, além da criação de um programa de educação sobre os problemas ambientais nas escolas públicas, aliado à capacitação dos professores para isso; à participação popular: disseminação e aprofundamento da participação popular, tanto na escala do bairro quanto na escala do município; e à gestão ambiental pública: fiscalização mais efetiva das atividades empresariais, melhoria dos serviços de limpeza pública, assim como elaboração do Plano de Saneamento Básico e do Plano Integrado de Resíduos Sólidos do município.

Desse modo, essas medidas poderão resultar em ganhos significativos, a partir da consideração de aspectos subjetivos, até então considerados de menor importância ou mesmo negligenciados durante o processo de planejamento e de gestão ambiental das cidades. Acredita-se, portanto, que um tratamento mais abrangente sobre a questão ambiental possibilitará resultados mais sólidos quanto à melhoria da qualidade ambiental e, consequentemente, à qualidade de vida da população.

\section{Referências}

AMORIM FILHO, O. B. Topofilia, topofobia e topocídio em MG. In: DEL RIO, V.; OLIVEIRA, L. (Orgs). Percepção ambiental - a experiência brasileira. 2. ed. São Paulo: Studio Nobel; UFSCar, 1999. p. 139-52.

BANDEIRA, T. O. Infraestrutura e qualidade ambiental urbana: uma avaliação 
de municípios do Estado do Tocantins a partir de indicadores socioambientais. 2010. 203f. Dissertação (Mestrado em Ciências do Ambiente) - Universidade Federal do Tocantins, Campus Universitário de Palmas. Palmas, TO, 2010.

BATISTA, P. T. O meio ambiente, as cidades, as árvores urbanas e a SBAU. Brasília, DF: Sociedade Brasileira de Arborização Urbana, 2006. Disponível em: <http://www.sbau.org.br/materias_paulo_detarso.html>. Acesso em: 25 nov. 2012.

BORJA, P. C. Metodologia para a avaliação da qualidade ambiental urbana em nível local. Salvador: FAUFBA, 1997. Disponível em: <http://www.bvsde.paho.org/bvsaidis/impactos/peru/braiaa222.pdf >. Acesso em: 15 jun. 2011.

CORRÊA, R. L. O espaço urbano. São Paulo: Ática, 1995. (Série Princípios).

GIORGI, A. Sobre o método fenomenológico utilizado como modo de pesquisa qualitativa nas ciências humanas: teoria, prática e avaliação. In: POUPART, D. et. al. (Org). A pesquisa qualitativa: enfoques epistemológicos e metodológicos. Petrópolis: Vozes, 2008.

GOMES, M. A. S.; SOARES, B. R. Reflexões sobre a qualidade ambiental urbana. Estudos Geográficos, Rio Claro, v. 2, n. 2, p. 21-30, jul-dez 2004.

INSTITUTO BRASILEIRO DE GEOGRAFIA E ESTATÍSTICA - IBGE. Site Oficial. Rio de Janeiro: IBGE, 2011a.

Disponível em: <http://www.ibge.gov.br/cidadesat/topwindow.htm?1>. Acesso em: 26 jul. 2011.

INSTITUTO BRASILEIRO DE GEOGRAFIA E ESTATÍSTICA - IBGE. Luís Eduardo Magalhães - BA. Rio de Janeiro: IBGE, 2011b. Disponível em: $\langle$ http://biblioteca.ibge.gov.br/visualizacao/dtbs/bahia/luiseduardomagalhaes.pdf $>$. Acesso em: 15 ago. 2011.

LACERDA, N. P. et al. Percepção dos residentes sobre a arborização da cidade de São José de Piranhas - PB. REVSBAU, Piracicaba - SP, v.5, n.4, p.81-95, 2010.

LUENGO, F., G. Elementos para la definición y evaluación de la calidad ambiental urbana: una propuesta teórico-metodológica. Seminário Latinoamericano de Calidad de Vida Urbana, 4, 1998. Tandil. Anais... Tandil: (s. n.), 1998. Disponível em: <http://www.perfilciutat.net/fitxers/IVSL_A4.pdf>. Acesso em: 24 jul. 2011.

LYNCH, K. A boa forma da cidade. Lisboa: Edições 70, 1999. 
MACHADO, L. M. C. P. Qualidade ambiental: indicadores quantitativos e perceptivos. In: MARTOS, H. L.; MAIA, N. B. (Orgs.). Indicadores ambientais. Sorocaba: s.n., 1997, p.15-21.

MINAKI, C.; AMORIM, M. C. C. T. Espaços urbanos e qualidade ambiental - um enfoque da paisagem. Revista Formação, São Paulo, UNESP, v. 1, n.14, p. 67-82, 2007. Disponível em:

<http://revista.fct.unesp.br/index.php/formacao/article/viewFile/699/722>. Acessos em: 20 jun. 2011.

MUCELIN, C. A.; BELLINI, M. Lixo e impactos ambientais perceptíveis no ecossistema urbano. Sociedade \& Natureza (on line), Uberlândia, v. 20, n.1, p. 111-124, jun. 2008. Disponível em:

<http://www.scielo.br/pdf/sn/v20n1/a08v20n1.pdf>. Acesso em: 9 out. 2012.

OLIVEIRA, A. A. Desigualdades sócio-espaciais na cidade do agronegócio: um estudo de caso em Luís Eduardo Magalhães - BA. 2012. 118 f. Trabalho de Conclusão de Curso (Graduação em Geografia) - Universidade Federal da Bahia, Instituto de Ciências Ambientais e Desenvolvimento Sustentável, Barreiras, BA.

PIVETTA, K. F. L.; SILVA FILHO, D. F. Arborização urbana. Jaboticabal (SP): UNESP/FCAV/FUNEP, 2002. (Boletim Acadêmico: Série Arborização Urbana). Disponível em: <http://www.uesb.br/flower/alunos/pdfs/arborizacao_urbana\%20Khatia.pdf>. Acesso em: 20 out. 2010.

RIBEIRO, H. Comunicação como Instrumento do Planejamento e da Gestão Ambientais. In: VARGAS, H. C.; RIBEIRO, H. (Orgs). Novos Instrumentos de Gestão Ambiental Urbana. 1. ed. São Paulo: Editora da Universidade de São Paulo, 2004.

RODRIGUES, A. M. Produção e consumo do e no espaço: problemática ambiental urbana. São Paulo: Hucitec, 1998.

RODRIGUES, T. D. et al. Percepção sobre arborização urbana de moradores em três áreas de Pires do Rio - Goiás. Revista de Estudos Ambientais, Blumenau, SC, IPA/FURB, v.12, n. 2, p. 47-61, jul./dez. 2010. Disponível em: <http://proxy.furb.br/ojs/index.php/rea/article/view/1893/1450>. Acesso em: 24 jul. 2012.

SANTOS, C. C. M. Os cerrados da Bahia sob a lógica do capital. Revista IDeAS, Interfaces em Desenvolvimento, Agricultura e Sociedade, v. 2, n. 1, p. 76-108, jan./jun. 2008. Disponível em: <dialnet.unirioja.es/descarga/articulo/4048129.pdf>. Acesso em: 20 jul. 2011. 
SILVA, C. U. T. Planejamento e gestão ambientais urbanos do município de Palmas (TO): uma abordagem fenomenológica a partir do poder público municipal. 2012. 129 f. Dissertação (Mestrado em Ciências do Ambiente) Universidade Federal do Tocantins, Campus Universitário de Palmas, Palmas, TO.

SILVA, M. L. G. Análise da qualidade ambiental urbana da bacia hidrográfica da Lagoa da Conceição. Florianópolis, SC: Universidade Federal de Santa Catarina, 2002.

SOUZA, L. B. Percepção dos riscos de escorregamentos na Vila Mello Reis, Juiz de Fora (MG): contribuição ao planejamento e à gestão urbanos. 2006. $201 \mathrm{f}$. Tese (Doutorado em Geografia) - Universidade Estadual Paulista, Rio Claro, SP.

SOUZA, M. L. Mudar a cidade: uma introdução crítica ao planejamento e gestão urbanos. Rio de Janeiro: Bertrand, 2004.

SOUZA, M. L. A prisão e a ágora: reflexões em torno da democratização do planejamento e da gestão das cidades. Rio de Janeiro: Bertrand, 2006.

STURZA, J. A. I.; MACHADO, L. M. C. P. O sentido de lugar em Rondonópolis MT e o topocídio do cerrado: uma contribuição aos estudos de cognição ambiental. IN: GERALDI, L. H.; CARVALHO, P. (Orgs). Geografia: ações e reflexões. São Paulo: UNESP, 2005.

TROPPMAIR, H. Atlas da qualidade ambiental e de vida de Rio Claro. Rio Claro: UNESP; IGCE, 1992.

TUAN, Y. Topofilia: um estudo da percepção, atitudes e valores do meio ambiente. São Paulo: Difel, 1980.

TUAN, Y. Espaço e lugar: a perspectiva da experiência. São Paulo: Difel, 1983. $250 \mathrm{p}$.

UGEDA JÚNIOR, J. C.; AMORIM, M. C. C. T. Urbanização brasileira, planejamento urbano e planejamento da paisagem. In: CONGRESSO DO MEIO AMBIENTE DA AUGM, 2009, São Carlos - SP. Anais de eventos da UFSCAR. São Carlos - SP: Edufscar, 2009. v. 5.

VIEIRA, V. S. O governo local e a promoção econômica a partir do marketing territorial no município de Luís Eduardo Magalhães/Bahia. 2007. 170 f. Dissertação (Mestrado em Cultura, Memória e Desenvolvimento Regional) Universidade do Estado da Bahia, Santo Antonio de Jesus, BA. 


\section{WHYTE, A.V. T. Guidelines for fields studies in environmental perception.} Paris: UNESCO, 1977. (MAB Technical Notes 5).

\section{Franco Porto dos Santos}

Biólogo do Instituto Caturama de Sustentabilidade.

Mestre em Ciências do Ambiente pela Universidade Federal do Tocantins. Núcleo de

Educação, Meio Ambiente e Desenvolvimento. Rua 07, quadra 15 s/no, Jardim dos Ipês 77500-000 - Porto Nacional, TO.

E-mail: francobio@hotmail.com

\section{Lucas Barbosa e Souza}

Doutor em Geografia pela Universidade Estadual Paulista. Professor dos Cursos de Mestrado em Ciências do Ambiente e em Geografia da Universidade Federal do

Tocantins. Núcleo de Educação, Meio Ambiente e Desenvolvimento.

Rua 07, quadra 15 s/nº, Jardim dos Ipês -77500-000 - Porto Nacional, TO.

E-mail: lbsgeo@uft.edu.br

Recebido para publicação em setembro de 2013 Aprovado para publicação em dezembro de 2013 